\title{
Detection of quantitative trait loci for mineral content of Nelore longissimus dorsi muscle
}

\author{
Polyana C Tizioto ${ }^{1,2}$, Jeremy F Taylor ${ }^{2}$, Jared E Decker ${ }^{2}$, Caio F Gromboni ${ }^{3}$, Mauricio A Mudadu ${ }^{4}$, Robert D Schnabel ${ }^{2}$, \\ Luiz L Coutinho ${ }^{5}$, Gerson B Mourão ${ }^{5}$, Priscila SN Oliveira ${ }^{1}$, Marcela M Souza', James M Reecy ${ }^{7}$, Renata T Nassu', \\ Flavia A Bressani ${ }^{4}$, Patricia Tholon ${ }^{4}$, Tad S Sonstegard ${ }^{6}$, Mauricio M Alencar ${ }^{4}$, Rymer R Tullio ${ }^{4}$, Ana RA Nogueira ${ }^{4}$ \\ and Luciana CA Regitano ${ }^{*}$
}

\begin{abstract}
Background: Beef cattle require dietary minerals for optimal health, production and reproduction. Concentrations of minerals in tissues are at least partly genetically determined. Mapping genomic regions that affect the mineral content of bovine longissimus dorsi muscle can contribute to the identification of genes that control mineral balance, transportation, absorption and excretion and that could be associated to metabolic disorders.

Methods: We applied a genome-wide association strategy and genotyped 373 Nelore steers from 34 half-sib families with the Illumina BovineHD BeadChip. Genome-wide association analysis was performed for mineral content of longissimus dorsi muscle using a Bayesian approach implemented in the GenSel software.
\end{abstract}

Results: Muscle mineral content in Bos indicus cattle was moderately heritable, with estimates ranging from 0.29 to 0.36. Our results suggest that variation in mineral content is influenced by numerous small-effect QTL (quantitative trait loci) but a large-effect QTL that explained 6.5\% of the additive genetic variance in iron content was detected at 72 $\mathrm{Mb}$ on bovine chromosome 12. Most of the candidate genes present in the QTL regions for mineral content were involved in signal transduction, signaling pathways via integral (also called intrinsic) membrane proteins, transcription regulation or metal ion binding.

Conclusions: This study identified QTL and candidate genes that affect the mineral content of skeletal muscle. Our findings provide the first step towards understanding the molecular basis of mineral balance in bovine muscle and can also serve as a basis for the study of mineral balance in other organisms.

\section{Background}

Genome-wide association studies (GWAS) can be used to identify quantitative trait loci (QTL) associated with complex traits and to better understand which genes and biological mechanisms underlie phenotypic variation. Knowledge on the genes that affect mineral content in beef cattle would provide valuable insights into ruminant metabolic diseases [1], assist in animal diet formulation, and allow the development of beef products that improve human nutrition. Beef cattle require many dietary minerals for optimal health, production and reproduction. There are two categories of minerals, i.e., macrominerals that are needed in larger amounts and trace minerals.

\footnotetext{
* Correspondence: luciana.regitano@embrapa.br

${ }^{4}$ Embrapa Southeast Livestock, São Carlos, SP, Brazil

Full list of author information is available at the end of the article
}

Diets that do not provide adequate amounts of these minerals can lead to animal health problems and losses in profitability for producers. However, because trace minerals are required only in very small amounts, inadequate supplementation may have negative effects on animal health.

Previous studies on the Nelore cattle population used here [2,3] and on other Bos taurus populations [4] have suggested that muscle mineral content may influence beef quality traits, such as meat tenderness, possibly because the effect of the genes that control these traits depends on the presence of specific minerals. For example, reduced calcium availability may affect the calpaincalpastatin system, which plays a major role in postmortem proteolysis and meat tenderization [5-7], as well as being crucial for muscle contraction.

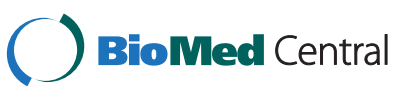

(c) 2015 Tizioto et al.; licensee BioMed Central. This is an Open Access article distributed under the terms of the Creative Commons Attribution License (http://creativecommons.org/licenses/by/2.0), which permits unrestricted use, distribution, and reproduction in any medium, provided the original work is properly credited. The Creative Commons Public Domain Dedication waiver (http://creativecommons.org/publicdomain/zero/1.0/) applies to the data made available in this article unless otherwise stated. 
The concentrations of minerals in the muscle depend on mineral supplementation and excretion [1], but can also be affected by environmental effects such as birthplace, age and breed [3]. Furthermore, it has been shown that mineral content in tissues is in part genetically determined and heritable $[8,9]$ and that the genes involved may act via receptor, transporter and chaperone proteins [1].

Thus, a genome-wide association study of the mineral content in beef muscle was undertaken to identify regions in the bovine genome that control variation in mineral balance, transportation, absorption and excretion. We identified QTL regions that contain genes that could be related to variation in the amounts of arsenic (As), calcium (Ca), chromium ( $\mathrm{Cr})$, cobalt (Co), copper $(\mathrm{Cu})$, iron $(\mathrm{Fe})$, magnesium $(\mathrm{Mg})$, manganese $(\mathrm{Mn})$, phosphorus $(\mathrm{P})$, potassium $(\mathrm{K})$, selenium $(\mathrm{Se})$, sodium $(\mathrm{Na})$, sulfur $(\mathrm{S})$ and zinc $(\mathrm{Zn})$, in the longissimus dorsi muscle of Nelore cattle.

\section{Methods \\ Animals}

The research protocol was approved by the Embrapa Southeast Livestock (São Carlos, São Paulo, Brazil) ethics committee. Half-sib families, totaling 373 Nelore steers, were produced from 34 sires chosen to represent the main commercial lineages in Brazil, i.e., different genealogies, and based on the average price of semen used by Brazilian beef cattle producers in order to sample bulls widely used in the country. These half-sib families were produced during two different breeding seasons by artificial insemination of commercial and purebred Nelore dams with semen from the 34 purebred Nelore sires. On average, 20 offspring per sire were produced of which the steer progeny were used in this study.

Calves were born and raised on four farms and transported to a feedlot at Embrapa Southeast Livestock when they were about 21 months of age, where they were maintained in individual $(n=158)$ or collective pens $(n=215$, with 10 animals per collective pen) and allowed ad libitum access to feed and water. The adaptation period to the diet, before allocation to the pens, was approximately 28 days. Animals were fed twice daily. Diets contained $40 \%$ dry matter (DM) in the form of corn silage with $13.5 \%$ crude protein; and energy densities of $2.8 \mathrm{Mcal}$ metabolizable energy per $\mathrm{kg}$ DM. The remaining $60 \%$ of $\mathrm{DM}$ was in the form of concentrate, and contained ground corn, soybean meal, cotton seed, soybean hulls, limestone, a mineral mixture, urea and monensin (Rumensin $\left.{ }^{\circ}\right)$. Steers were slaughtered after about 90 days of feeding at a smallscale slaughter and processing facility at an average age of 734 days and a mean weight of $383.2 \mathrm{~kg}$ when backfat thickness reached about $5 \mathrm{~mm}$, which was evaluated by ultrasound.

\section{DNA extraction and genotyping}

Five $\mathrm{mL}$ blood samples were collected from each steer and DNA extractions were performed using a salting out method [10]. All animals were genotyped using the Illumina BovineHD BeadChip (Illumina Inc., San Diego, CA) either at the USDA ARS Bovine Functional Genomics Laboratory in Beltsville (MD) or at the ESALQ Genomics Center, Piracicaba, São Paulo, Brazil. Genotypes were called using the Illumina Genome Studio software [11]. Samples were filtered based on a call rate [12] greater than $85 \%$ and heterozygosity greater than $40 \%$. Loci were deleted if their Illumina probe sequence could not be uniquely mapped to an autosome on the UMD3.1 reference assembly [13], if their call rate was less than $90 \%$, minor allele frequency was less than $0.5 \%$, or if they deviated severely from Hardy Weinberg equilibrium $\left(x^{2}>100.0\right)$, as described by Tizioto et al. [2]. Only autosomal genotypes were used in the association analysis.

\section{Phenotype collection}

At slaughter, $2.5 \mathrm{~cm}$ thick steaks were sampled as a cross section of the longissimus dorsi muscle between the $11^{\text {th }}$ and $13^{\text {th }}$ ribs. Mineral phenotypes were measured as described by Tizioto et al. [3]. The longissimus dorsi muscle was used because it is a major commercialized beef cut and is conventionally used for measuring most meat quality traits [14]. Briefly, an entire steak was lyophilized; homogenized and $100 \mathrm{mg}$ was sampled for chemical analyses. Analytical grade reagents and ultrapure water (Milli-Q system, Millipore, Billerica, MA, USA) were used and standard solutions were certified with plasma grade and high purity materials from SpecSol (Jacareí, SP, Brazil). A closed-vessel microwave digestion system (Ethos-1600, Milestone-MLS, Sorisole, Italy) equipped with optic fiber temperature and pressure sensors was used for digestion of the sample. Longissimus dorsi muscle samples were digested in the microwave vessel using $2 \mathrm{~mL}$ of sub-boiled concentrated $\mathrm{HNO}_{3}, 2 \mathrm{~mL}$ of $\mathrm{H}_{2} \mathrm{O}_{2}(30 \% \mathrm{w} / \mathrm{w})$ and $6.0 \mathrm{~mL}$ of ultrapure water in closed vessels made of perfluoroalkoxy copolymer resin (PFA). A three-step heating cycle was applied: (1) a first heating ramp at $120^{\circ} \mathrm{C}(1300 \mathrm{~W})$ for $10 \mathrm{~min}$; (2) a second heating ramp at $170^{\circ} \mathrm{C}(1500 \mathrm{~W})$ for $15 \mathrm{~min}$; and (3) a heat treatment at $170^{\circ} \mathrm{C}$ for $35 \mathrm{~min}$.

After digestion, samples and blank solutions were transferred to $10.0 \mathrm{~mL}$ volumetric flasks and volumes were completed with ultrapure water. The mineral contents were determined by Vista Pro-CCD ICP-OES spectrometer with radial view (Varian, Mulgrave, Australia). Excitation wavelengths were chosen to minimize spectral interference and produce the highest intensity emission for each element. A linear calibration was calculated with up to five points from preparations using standard analytical solutions. 
Accuracy and precision of the method used to measure the mineral amounts were evaluated by measuring the recovery level and relative standard deviation of the certified reference materials Bovine Liver 1557b and Bovine Muscle 8414 $(\mathrm{N}=3)$ from the National Institute of Standards and Technology (Gaithersburg, MD, USA). The experiment was carried out in triplicate. Recovery values were calculated according to the values obtained for the certified reference samples.

\section{Genome-wide association analysis}

Missing genotypes were imputed using BEAGLE v3.3.2 [15] without the use of pedigree information. Longissimus dorsi muscle mineral content was analyzed under a Bayesian model using GenSel software [16], as explained below, using an approach similar to that described by Tizioto et al. [2] to identify genomic regions influencing these phenotypes. First, BayesC [17], was used to estimate additive genetic and residual variances, assuming a $\pi$ parameter (prior distribution for $\theta$ ) value of 0 (i.e., assuming that all SNPs contributed to explaining genetic variance in each trait). From these estimates the phenotypic variance was estimated as the sum of the additive genetic and residual variance components and the heritability as the ratio of additive genetic to phenotypic variances. The estimates of additive genetic and residual variance from the Bayes $C$ analyses were then used to run the BayesB analyses [18] to estimate SNP effects. The parameter $\pi$ was set to 0.9995 such that the number of SNP effects to be estimated was less than the number of animals with data $(449364 \times(1-\pi)=224$ SNPs $)$, as suggested by Mateescu et al. [9]. The BayesB analysis fits separate variances for each SNP in the model, which allows large-effect SNPs to be estimated without excessively regressing their effects towards 0 . The statistical model included the fixed effects of six contemporary groups that were formed using combinations of birth $(n=4)$ and feedlot location $(n=2)$ and breeding season $(n=2)$. The animal's age at slaughter was included as a covariate.

The genomic regions that included the 224 SNPs that had the largest posterior probability [19] of being incorporated in the model for each trait were examined separately for candidate genes within $\pm 100 \mathrm{~kb}$ of each SNP using Map Viewer (http://www.ncbi.nlm.nih.gov/mapview/). The enriched pathways and functional gene clusters that involved the candidate genes within the associated genomic regions were identified using the Database for Annotation, Visualization and Integrated Discovery (DAVID) software [20]. In addition to estimating single SNP effects, Gensel software estimates the proportion of additive genetic variance that is explained by each $1-\mathrm{Mb}$ genomic window for each trait which was considered to be a QTL in this study and it was also used to identify potential candidate genes.

\section{Results}

Summary statistics for mineral content

Certified reference materials were evaluated to ensure the accuracy of the sample preparation procedure. The recovery values and triplicate deviations of the minerals in certified reference muscle samples ranged from 92.3 to $127.3 \%$ and 2 to 11.2 , respectively. Reasonable agreement was observed between samples and the certified values [21], which indicated the effective recovery of analytes after digestion and their accurate detection.

The raw means, variance components and heritability estimates generated by the BayesC analyses are in Table 1. Heritability estimates for all mineral contents were medium to high $(0.29-0.36)$.

\section{Genome-wide association study and underlying gene annotations}

After filtering SNPs based on call rate, allele frequency and Hardy-Weinberg equilibrium, and imputing $0.80 \%$ of missing genotypes, 449364 loci were available for the GWAS. Based on the number of available markers and the $\pi$ parameter $(0.9995)$, we calculated the number of SNPs that had the largest posterior probability which were used to perform functional annotation (449 $364 \times$ $(1-\pi)=224$ SNPs). The GWAS identified regions across the genome that harbored QTL for all minerals analyzed in this study. Most of the identified QTL were of smalleffect (i.e., explained less than $1 \%$ of the additive genetic variance in each trait). A few large-effect QTL were found.

\begin{tabular}{|c|c|c|c|c|}
\hline Trait & Mean $(\mathrm{mg} / \mathrm{kg}) \pm \mathrm{SE}$ & $\sigma_{e}^{2}$ & $\sigma_{a}^{2}$ & $h^{2}$ \\
\hline As & $0.4 \pm 0.001$ & 0.18 & 0.09 & 0.34 \\
\hline $\mathrm{Ca}$ & $164.3 \pm 5.2$ & 0.05 & 0.02 & 0.31 \\
\hline $\mathrm{Cr}$ & $0.4 \pm 0.03$ & 0.24 & 0.13 & 0.36 \\
\hline $\mathrm{Co}$ & $0.01 \pm 0.0007$ & 0.12 & 0.06 & 0.33 \\
\hline $\mathrm{Cu}$ & $1.8 \pm 0.05$ & 0.04 & 0.02 & 0.30 \\
\hline $\mathrm{Fe}$ & $44.7 \pm 1.6$ & 0.31 & 0.15 & 0.32 \\
\hline $\mathrm{Mg}$ & $759.5 \pm 7.6$ & 0.03 & 0.01 & 0.29 \\
\hline $\mathrm{Mn}$ & $0.19 \pm 0.01$ & 0.31 & 0.16 & 0.33 \\
\hline$P$ & $7356.4 \pm 85.4$ & 0.04 & 0.01 & 0.29 \\
\hline K & $1077.5 \pm 13.7$ & 0.04 & 0.02 & 0.30 \\
\hline Se & $0.2 \pm 0.005$ & 0.05 & 0.02 & 0.32 \\
\hline $\mathrm{Na}$ & $1746.3 \pm 22.86$ & 0.04 & 0.02 & 0.29 \\
\hline S & $6287.7 \pm 84.6$ & 0.04 & 0.02 & 0.30 \\
\hline $\mathrm{Zn}$ & $79.8 \pm 1.2$ & 0.04 & 0.02 & 0.31 \\
\hline
\end{tabular}

$\mathrm{As}=$ arsenic, $\mathrm{Ca}=$ calcium, $\mathrm{Cr}=$ chromium, $\mathrm{Co}=$ cobalt, $\mathrm{Cu}=$ copper, $\mathrm{Fe}=$ iron, $\mathrm{Mg}=$ magnesium, $\mathrm{Mn}=$ manganese, $\mathrm{P}=$ phosphorus, $\mathrm{K}=$ potassium, $\mathrm{Se}=$ selenium, $\mathrm{Na}=$ sodium, $\mathrm{S}=$ sulfur and $\mathrm{Zn}=$ zinc; $\mathrm{SE}$ : standard error. 
A QTL that explained 6.5\% of the additive genetic variance for Fe content (Table 2) was detected at $72 \mathrm{Mb}$ on BTA12 (BTA for Bos taurus chromosome) (Figure 1). The genomic region that harbored this QTL includes genes from the ATP-binding cassette family (Table 2).

Other large-effect QTL were found for muscle contents of $\mathrm{Se}, \mathrm{Ca}$ and $\mathrm{Zn}$ and were respectively located on BTA11 at $22 \mathrm{Mb}$, BTA 8 at $56 \mathrm{Mb}$ and BTA 8 at $10 \mathrm{Mb}$, and explained 3.53, 2.59 and $2.5 \%$ of the additive genetic variance in these traits, respectively (Table 2, Figures 2, 3 and 4). These regions contain the following genes: transmembrane protein 178 (TMEM178), transmembrane channel-like proteins 5 and 7 (TMC5 and TMC7), ubiquitin specific peptidases (USP45 and USP46), sorting nexins 2 and 24 (SNX2 and SNX24) and scavenger receptors 3 and 5 (SCARA3 and SCARA5). The QTL with the greatest effect identified on BTA8 at $10 \mathrm{Mb}$, which explained $2.6 \%$ of the additive genetic variance of muscle content of $\mathrm{Zn}$, also explained $0.5 \%$ of the additive genetic variation for $\mathrm{Fe}$ concentration (Figure 5). Allele substitution effects for several SNPs located in this region were in the same direction for muscle contents of $\mathrm{Zn}$ and $\mathrm{Fe}$ and selection on this QTL could be used to improve the muscle concentrations of both $\mathrm{Fe}$ and $\mathrm{Zn}$. In addition, we identified other QTL for Zn content on BTA8 at 11, 12, 76 and $78 \mathrm{Mb}$. BTA8 harbors QTL that affect muscle contents of Fe, Zn and P (Figure 5). The BTA8 QTL at $72 \mathrm{Mb}$ associated with $\mathrm{Fe}$ content is in a region that harbors the scavenger receptor class $A$, member 5 (SCARA5) gene, which is involved in cellular iron homeostasis and transport [22], and is a good candidate gene for further studies.

Candidate genes within $100 \mathrm{~kb}$ of the most strongly associated SNPs [See Additional file 1: Table S1] were analyzed to search for functional pathways using DAVID. Most of the genes within these regions are involved in signal transduction, signaling pathways via integral proteins, regulation of transcription and metal ion binding [See Additional file 2: Table S2]. Gene clusters associated with QTL for Mg content are involved in transcription regulation and nucleotide binding. Solute carrier family genes were identified as being candidate genes across all mineral tissue contents.

\section{Discussion}

The recovery values and triplicate deviations observed for the mineral analyses were all within acceptable limits [21], which indicate that the measurement methodology for muscle mineral concentration was reliable. The mean concentrations of each mineral, especially for iron (Table 1), were higher than is generally observed for Bos taurus cattle $[4,23]$. This difference may be due to dietary, breed, or age at slaughter differences.

Table 2 Chromosome, location, number of SNPs, and percentage of additive genetic variation explained by the most important QTL regions associated with mineral concentration in muscle tissue of Nelore cattle

\begin{tabular}{|c|c|c|c|c|c|}
\hline Trait & $\mathrm{Chr}^{\mathrm{a}}$ & Position $(\mathrm{Mb})^{\mathbf{b}}$ & $\mathrm{Nb} \mathrm{SNPs}^{\mathrm{c}}$ & Variance $(\%)^{d}$ & Candidate genes \\
\hline$\overline{A r}$ & 25 & 17 & 227 & 1.1 & COQ7, TMC7,TMC5, GDE1, CCP110, KNOP1, IQCK, GPRC5B and GPR139 \\
\hline $\mathrm{Ca}$ & 8 & 56 & 126 & 2.6 & - \\
\hline $\mathrm{Cr}$ & 20 & 65 & 267 & 1.1 & MTRR, FASTKD3, ADCY2 and TRNAC-ACA \\
\hline $\mathrm{Cr}$ & 9 & 50 & 160 & 1.0 & ASCC3, TRNAC-GCA, SIM1, MCHR2, PRDM13, CCNC and USP45 \\
\hline Co & 6 & 70 & 300 & 0.5 & USP46, RASL11B, SCFD2, FIP1L1 and LNX1 \\
\hline $\mathrm{Cu}$ & 18 & 29 & 229 & 1.1 & TRNAA-AGC and CDH8 \\
\hline $\mathrm{Fe}$ & 12 & 72 & 94 & 6.5 & TRNAC-GCA \\
\hline $\mathrm{Fe}$ & 7 & 32 & 257 & 5.0 & PRDM6, PPIC, SNX24 and SNX2 \\
\hline $\mathrm{Mg}$ & 10 & 50 & 144 & 1.3 & FOXB1, BNIP2, GTF2A2, GCNT3 and FAM81A \\
\hline $\mathrm{Mn}$ & 6 & 66 & 219 & 0.7 & GABRG1, GABRA2, TRNAW-CCA and COX7B2 \\
\hline$P$ & 3 & 115 & 236 & 1.1 & SH3BP4 \\
\hline K & 10 & 50 & 144 & 1.2 & FOXB1, BNIP2, GTF2A2, GCNT3 and FAM81A \\
\hline Se & 11 & 22 & 243 & 3.5 & TMEM178 and THUMPD2 \\
\hline $\mathrm{Se}$ & 12 & 54 & 186 & 1.8 & POU4F1, RNF219, RBM26 and NDFIP2 \\
\hline $\mathrm{Na}$ & 6 & 35 & 184 & 0.4 & FARSB and CCSER1 \\
\hline S & 1 & 28 & 193 & 0.7 & TRNAS-GGA and GBE1 \\
\hline $\mathrm{Zn}$ & 8 & 10 & 218 & 2.5 & $\begin{array}{l}\text { FZD3, FBXO16, ZNF395, PNOC, TRNAG-GCC, ELP3, NUGGC, SCARA5, } \\
\text { PBK ESCO2, CCDC25 and SCARA3 }\end{array}$ \\
\hline
\end{tabular}

$\mathrm{As}=$ arsenic, $\mathrm{Ca}=$ calcium, $\mathrm{Cr}=$ chromium, $\mathrm{Co}=$ cobalt, $\mathrm{Cu}=$ copper, $\mathrm{Fe}=$ iron, $\mathrm{Mg}=$ magnesium, $\mathrm{Mn}=$ manganese, $\mathrm{P}=$ phosphorus, $\mathrm{K}=$ potassium, Se $=$ selenium, $\mathrm{Na}=$ sodium, $\mathrm{S}=$ sulfur and $\mathrm{Zn}=\mathrm{zinc}^{\mathrm{a}}{ }^{\mathrm{C}} \mathrm{Chr}=$ chromosome; ${ }^{\mathrm{b}}$ position of the QTL on the chromosome in Mb; ${ }^{\mathrm{C}}$ number of SNPs within the $1 \mathrm{Mb}$ window detected as harboring the QTL; ${ }^{d}$ percentage of the additive genetic variance explained by the $1 \mathrm{Mb}$ window estimated by calculating the variance of the molecular breeding values for all animals using the SNP effects for each window. 


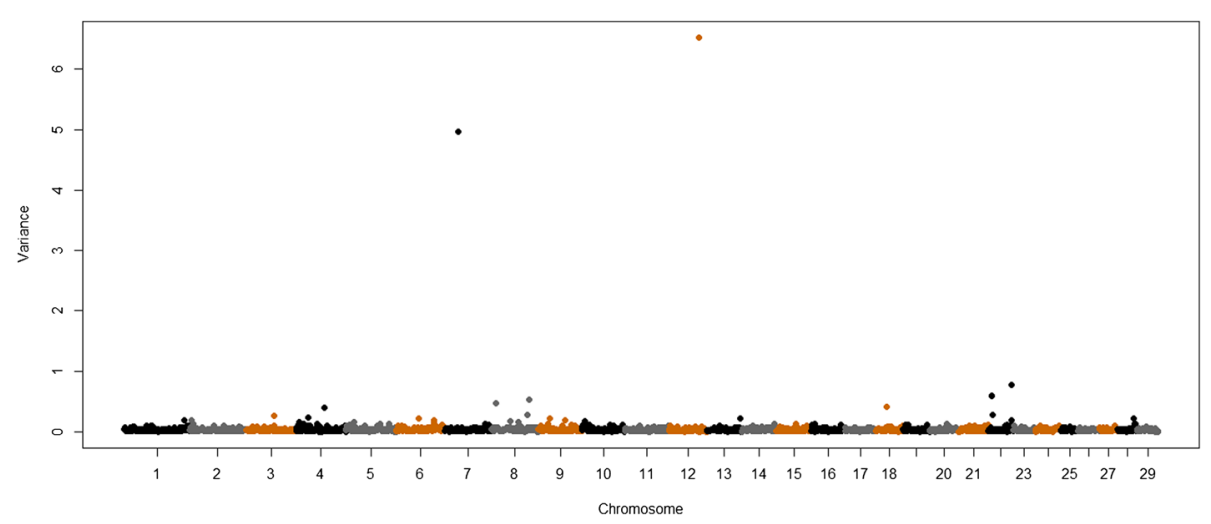

Figure 1 Genome-wide plot of additive genetic variance explained by 1-Mb marker windows for iron concentration of Nelore longissimus dorsi muscle.

The proportion of phenotypic variance explained by markers, considered to be a measure of heritability, indicates that these traits are at least partially heritable; however, we did not assess the accuracies of genomic predictions and the small animal sample size may have influenced these estimates of heritability. A similar study in the Angus bovine breed reported heritability estimates of $0.48,0.15$ and 0.06 for $\mathrm{Fe}, \mathrm{Na}$ and $\mathrm{Zn}$ concentrations, respectively, when an animal model using the numerator relationship matrix to model identity-by-descent between animals was used to estimate the variance components [9]. In that study, heritability estimates of 0 were obtained for $\mathrm{Mg}, \mathrm{Mn}, \mathrm{P}$ and $\mathrm{K}$ muscle content under the same model. However, when the BayesC module (which accounts for genomic relationships among animals) of the GenSel software was used, the proportion of phenotypic variance explained by genome-wide SNPs was $0.37,0.18$, $0.20,0.12,0.03,0.09$ and 0.17 for $\mathrm{Fe}, \mathrm{Mg}, \mathrm{Mn}, \mathrm{P}, \mathrm{K}, \mathrm{Na}$ and $\mathrm{Zn}$ content, respectively [9]. The differences between the proportions of phenotypic variance explained by marker genotypes and the heritability estimates obtained using an animal model with a pedigree-derived relationship matrix may be due to errors in the pedigree, lack of depth of pedigree to capture additional relationships, or selection of progeny within families for phenotyping (selection on the Mendelian sampling coefficient), all of which are captured in the genomic relationship matrix but not in the numerator relationship matrix.

The detection of similar functional gene clusters for all mineral measurements indicates that similar biological mechanisms appear to affect the contents of different minerals. Some coincident genes and QTL regions [See Additional file 1: Table S1 and Additional file 2: Table S2], located at the centromeric end of BTA8, were found to influence the concentrations of Fe, $\mathrm{Zn}$ and P (Figure 5). The SCARA5 gene (Table 2), which is involved in iron delivery [22] is located in this region of the bovine genome. Other QTL regions that contain genes encoding transmembrane proteins, such as TMEM178, TMC5, and TMC7, were also identified. These genes are intricately involved in the transport of various substrates across cell membranes and are driven by ion gradients [24].

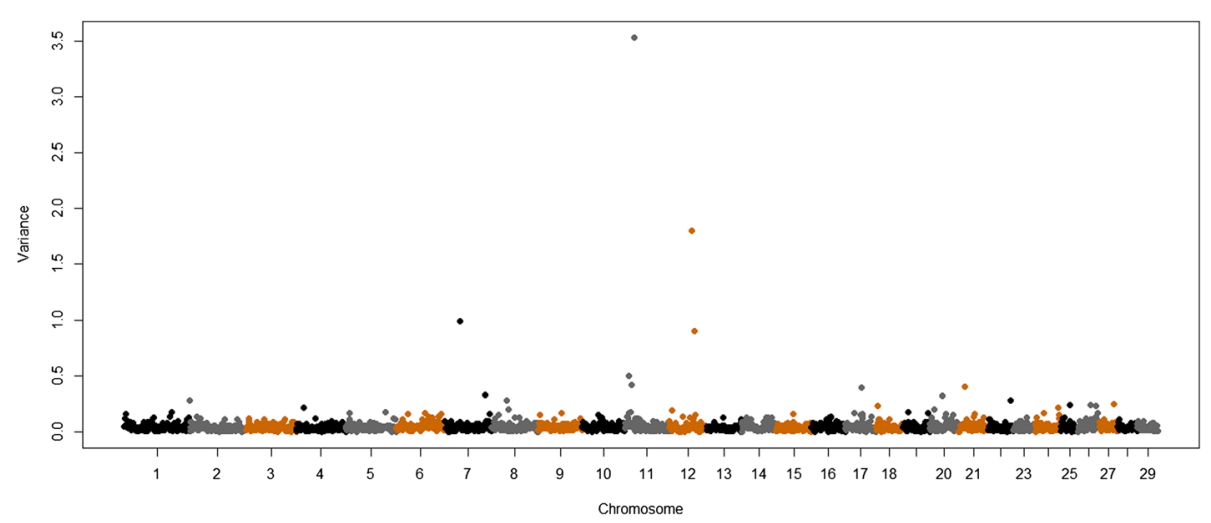

Figure 2 Genome-wide plot of additive genetic variance explained by 1-Mb marker windows for selenium concentration of Nelore longissimus dorsi muscle. 


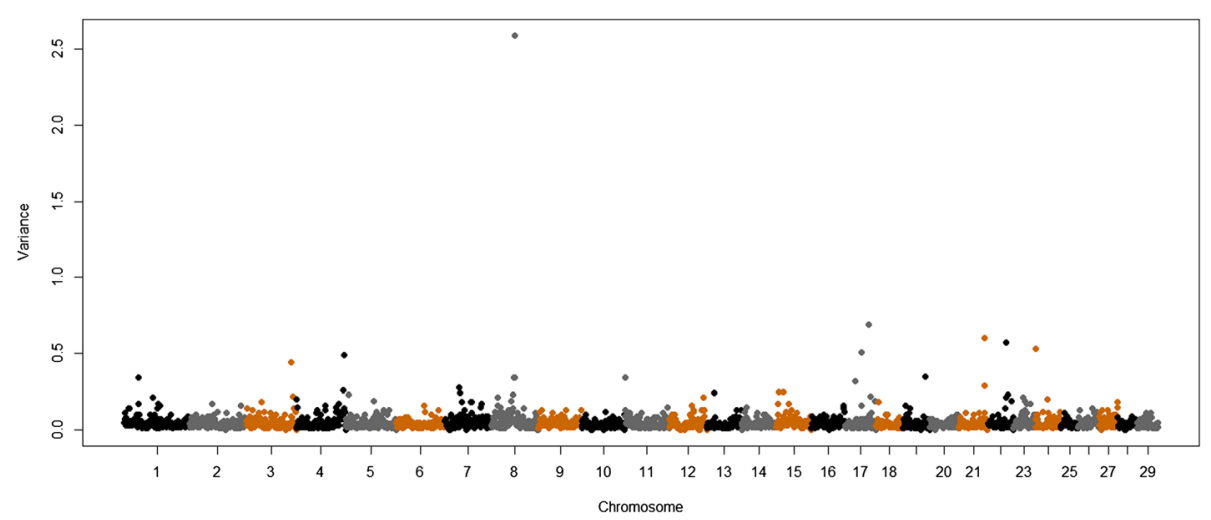

Figure 3 Genome-wide plot of additive genetic variance explained by 1-Mb marker windows for calcium concentration of Nelore longissimus dorsi muscle.

Influx systems of metal ions in cells are strongly regulated by both transcriptional and posttranscriptional control mechanisms [25]. Most candidate genes identified in this study as potentially affecting mineral concentrations are involved in signal transduction, signaling pathways via integral protein membranes, zinc-fingers, regulation of transcription and metal ion binding [See Additional file 2: Table S2], which reinforces the idea that the genetic architecture of muscle mineral concentration probably involves genes that control the transport and homeostasis of ions [1]. Genes that participate in the functions of integral membrane proteins and transmembrane proteins were found in regions that were associated with all mineral concentrations and may transport specific substrates across biological membranes depending on membrane potentials established by ion concentration [26]. Mutations in these genes could cause the abnormal function of these proteins and could influence mineral concentrations.

Iron is needed for several metabolic pathways that operate continuously at the molecular level and are essential to human life [27]. We found a large-effect QTL located on BTA12 that explained $6.5 \%$ of the genetic variance for this trait (Table 2); however, the major genomic region identified in the Angus breed and reported by Mateescu et al. [9] was not the same as that detected in this study. The QTL with the largest effect that was detected in Angus cattle was located on BTA15 and explained $4.8 \%$ of the genetic variance [9]. In fact, none of the large-effect QTL reported for muscle Fe content identified in Angus cattle [9] co-localized with those found in this study (Table 2). While a QTL at $62 \mathrm{Mb}$ on BTA1 explained $1.5 \%$ of the genetic variance for Fe content in Angus cattle, the same region in Nelore cattle explained only $0.05 \%$ of the genetic variance. Morris et al. [1] conducted a study in Jersey and Limousin back-cross calves to search for QTL that influenced the amount of minerals in liver, kidney and muscle using microsatellites and the regions of the genome that they identified as harboring large-effect QTL for Fe concentration also did not co-localize with either those detected in this study or those detected by Mateescu et al. [9].

A recent study demonstrated that different genomic regions influence meat quality traits in indicine and taurine cattle [2]. This finding could be due to differences in

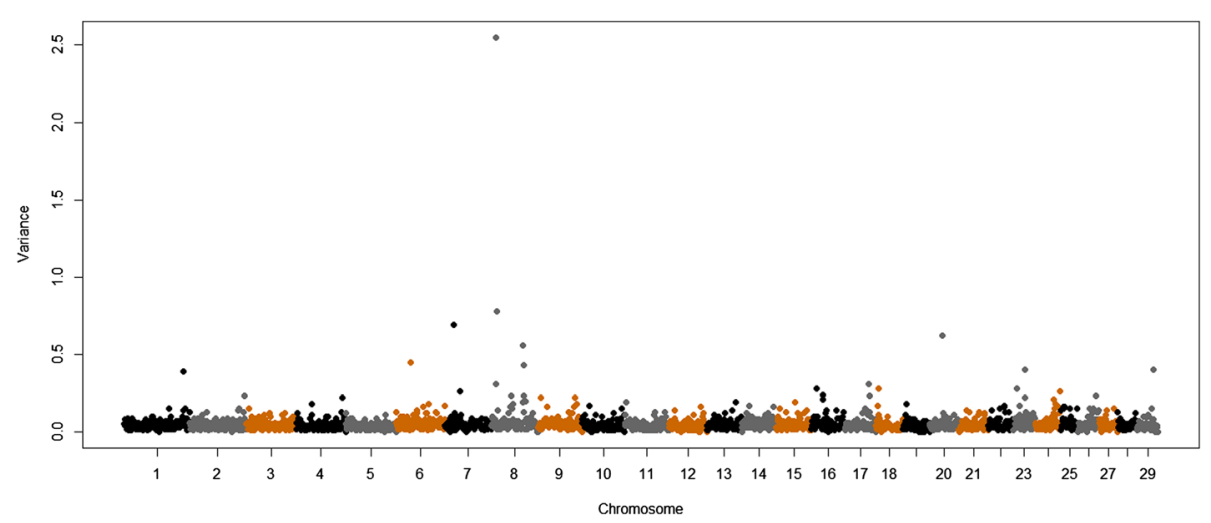

Figure 4 Genome-wide plot of additive genetic variance explained by 1-Mb marker windows for zinc concentration of Nelore longissimus dorsi muscle. 

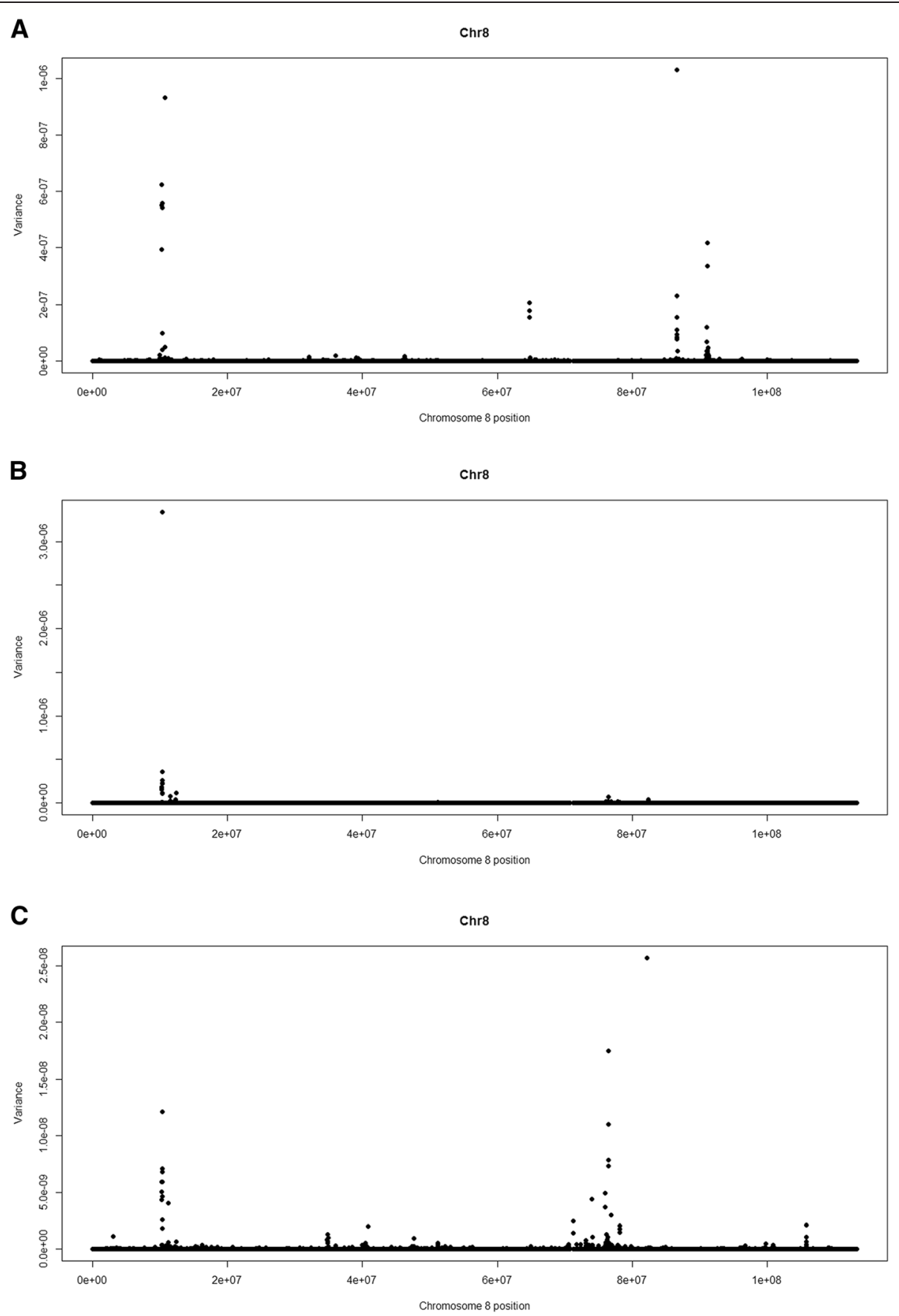

Figure 5 Plots of additive genetic variance explained by SNPs located on chromosome 8 for A: iron, B: zinc; C: phosphorus.

allele frequencies at the causal mutations and SNPs between these two subspecies and therefore to the extent of LD available to detect QTL [28] or to the divergence between indicine and taurine cattle leading to different QTL architectures. These inconsistencies may be also due to gene-gene (epistasis) or gene-environment interactions [29]. Given the limited number of animals used in this study, it is important to recall that not all the QTL may have been detected, which could also contribute to the differences found between this study and a similar study performed in Angus cattle [9]. Another reason for these inconsistencies could be the difference in resolution of the genotyping platform used. The Illumina BovineHD array used in this study has a considerably higher resolution than the previously used BovineSNP50 assay [9] or microsatellite scans [1], which can allow identification of genomic regions that were not identified in the lower resolution scans. 
Genes from the ATP-binding cassette family were found in the region that contained the large-effect QTL for $\mathrm{Fe}$ in the Nelore breed on BTA12. ABC proteins transport a number of substrates, including metal ions across the plasma membrane and across intracellular membranes [30]. Numerous genes that are involved in ion transport were candidates for the QTL that affect mineral content. Candidate genes that are involved in sodium transport include sodium channel as voltage-gated, type III, beta subunit (SCN3B), renal sodium/dicarboxylate cotransporter (SLC13A2), sodium channel, voltage-gated, type IV, beta subunit $(S C N 4 B)$ and in ion channel activity such as SCN3B, chloride intracellular channel 5 (CLIC5), sodium channel, voltage-gated, type IV, beta subunit (SCN4B), and potassium inwardly-rectifying channel, subfamily J, member 11 (KCNJ11) were identified specifically as candidates for $\mathrm{Na}$ concentration [See Additional file 1: Table S1].

Many more phenotypic records and further validation in other populations are necessary to accurately estimate the effects of the detected QTL before this information can be efficiently used in animal breeding programs. Despite inconsistencies in the regions identified that harbor large-effect QTL in Angus and Nelore cattle, the functional gene clusters and pathways identified based on candidate gene lists that were generated in both studies indicated that the QTL operate within the same pathways. Some gene networks such as the ATP-binding cassette family genes that play a role in Fe concentration were also reported by Mateescu et al. [9].

Studies on the identification of QTL associated with mineral concentration in different tissues have only recently been performed [1,9] and the mechanisms that control mineral homeostasis remain poorly understood. The increased interest in GWAS is due to the use of molecular markers to improve the accuracy of breeding value estimation and to increase our understanding of the genetic control of important production traits. Moreover, the identification of genes responsible for variation in traits may also provide insight into the biological mechanisms that underlie variation and the likely effects of selection on these polymorphisms [31].

In addition to production efficiency, beef cattle improvement programs should begin to consider traits that influence animal health and that could also benefit to human health [9], such as the mineral content of muscle/beef. High-density SNP genotyping has been used for more than five years to explain variation in quantitative traits of livestock; however, the underlying mechanisms that affect genetic variation are still poorly understood.

\section{Conclusions}

Several genomic regions associated with mineral composition of longissimus dorsi muscle were identified across all chromosomes, which reveals the polygenic nature of these traits. We identified a comprehensive list of candidate genes that may underlie the identified QTL regions and that are related to mineral transport and homeostasis [See Additional file 1: Table S1 and Additional file 2: Table S2]. Further validation studies and investigations to identify the causal mutations are necessary. This study provides the first step towards the understanding of the molecular basis of mineral concentration in muscle, which likely involves many genes. The lessons learned from elucidating the genetic architecture of mineral balance in bovine muscle could be used as a model for metabolic diseases in other organisms. This information may also be useful to outline strategies to improve the mineral concentration of muscle and enhance nutritional attributes; however, animal breeding programs should not prioritize these features in the near future, due to the limited current cost-effectiveness.

\section{Additional files}

Additional file 1: Table S1. Summary of enriched gene clusters from DAVID for identified genes for arsenic, calcium, chromium, cobalt, copper, iron, magnesium, manganese, phosphorus, potassium, selenium, sodium, sulfur and zinc in the longissimus dorsi muscle of Nelore cattle. Enriched gene clusters from DAVID analysis for candidate genes located in genomic regions associated with each mineral content. Tabs are divided by mineral type.

Additional file 2: Table S2. Summary of SNP effects for arsenic, calcium, chromium, cobalt, copper, iron, magnesium, manganese, phosphorus, potassium, selenium, sodium, sulfur and zinc in the longissimus dorsi muscle of Nelore cattle. Summary of effects of 224 markers that had the largest posterior probability of being incorporated in the model for each trait. Tabs are divided by mineral type.

\section{Competing interests}

The authors declare that they have no competing interests.

\section{Authors' contributions}

PCT, CFG, LLC, MMA ARAN and LCAR conceived and designed the experiment; PCT, CFG, PSNO, MMS, RTN, FAB and RRT performed the experiments; PCT, JFT, JED, MAM, RDS, GBM, JMR, PT, TSS and LCAR performed analyses and interpreted the results; PCT, JFT, LLC and LCAR drafted and revised the manuscript. All authors read and approved the final manuscript.

\section{Acknowledgements}

We thank Dr Gustavo Gasparin and Dr Wilson Malagó Jr for technical assistance; Dr Michele Lopes do Nascimento, Dr Andrea Souza and MSc Amália Saturnino for monitoring the feedlots; Dr Michel EB Yamaguishi and BSc Fabio D Vieira for technical assistance with database maintenance, Dr Dorian Garrick for data analysis support, the University of Missouri for accepting the first author as a visiting scholar, and the National Council of Technological and Scientific Development (CNPq) for providing fellowships to GB Mourão, LL Coutinho, MM Alencar, ARA Nogueira and LCA Regitano, and the scholarship provided to CF Gromboni. We also thank São Paulo Research Foundation (FAPESP) for providing scholarships \#2010/06515-4 and \#2012/01502-7 to PC Tizioto.

Author details

'Department of Genetics and Evolution, Federal University of Sao Carlos, São Carlos, SP, Brazil. 'Division of Animal Sciences, University of Missouri, Columbia, MO, USA. ${ }^{3}$ Federal Institute of Education, Bahia Science and 
Technology, Valença, BA, Brazil. " Embrapa Southeast Livestock, São Carlos, SP, Brazil. ${ }^{5}$ Department of Animal Science, University of São Paulo/ESALQ, Piracicaba, SP, Brazil. ${ }^{6}$ United States Department of Agriculture (USDA), Agricultural Research Service, Beltsville, MD, USA. ${ }^{7}$ Department of Animal Science, lowa State University, Ames, IA, USA.

Received: 26 January 2014 Accepted: 12 December 2014 Published online: 11 March 2015

\section{References}

1. Morris CA, Bottema CDK, Cullen NG, Hickey SM, Knowles SO, Pitchford WS. Effects of quantitative trait loci and the myostatin locus on trace and macro elements (minerals) in bovine liver, muscle and kidney. Anim Genet. 2013;44:361-8

2. Tizioto PC, Decker JE, Taylor JF, Schnabel RD, Mudadu MA, Silva FL, et al. Genome scan for meat quality traits in Nelore beef cattle. Physiol Genomics. 2013:45:1012-20.

3. Tizioto PC, Gromboni CF, Nogueira ARA, de Souza MM, Mudadu MA, Tholon $P$, et al. Calcium and potassium content in beef: Influences on tenderness and associations with molecular markers in Nellore cattle. Meat Sci. 2014;96:436-40.

4. Pogge DJ, Lonergan SM, Hansen SL. Influence of supplementing vitamin C to yearling steers fed a high sulfur diet during the finishing period on meat color, tenderness and protein degradation, and fatty acid profile of the longissimus muscle. Meat Sci. 2014;97:419-27.

5. Page BT, Casas E, Heaton MP, Cullen NG, Hyndman DL, Morris CA, et al. Evaluation of single-nucleotide polymorphisms in CAPN1 for association with meat tenderness in cattle. J Anim Sci. 2002;80:3077-85.

6. Casas E, White SN, Wheeler TL, Shackelford SD, Koohmaraie M, Riley DG, et al. Effects of calpastatin and $\mu$-calpain markers in beef cattle on tenderness traits. J Anim Sci. 2006;84:520-5.

7. Schenkel FS, Miller SP, Jiang Z, Mandell IB, Ye X, Li H, et al. Association of a single nucleotide polymorphism in the calpastatin gene with carcass and meat quality traits of beef cattle. J Anim Sci. 2006;84:291-9.

8. Morris CA, Phua SH. Metabolic diseases in sheep and cattle. In: Bishop SC, Axford RFE, Nicholas FW, Owen FW, editors. Breeding for Disease Resistance in Farm Animals. 3rd ed. Cambridge: CABI; 2010. p. 317-34.

9. Mateescu RG, Garrick DJ, Tait Jr RG, Garmyn AJ, Duan Q, Liu Q, et al. Genomewide association study of concentrations of iron and other minerals in longissimus muscle of Angus cattle. J Anim Sci. 2013;91:3593-600.

10. Tizioto PC, Meirelles SL, Veneroni GB, Tullio RR, Rosa AN, Alencar MM, et al. A SNP in ASAP1 gene is associated with meat quality and production traits in Nelore breed. Meat Sci. 2012;92:855-7.

11. GenomeStudioTM Genotyping Module v1.0 User Guide: An integrated platform for data visualization and analysis. [http://ycga.yale.edu/lmages/ GenomeStudio_GT_Module_v1.0_UG_11319113_RevA_tcm240-21464.pdf]

12. Liu W, Di X, Yang G, Matsuzaki H, Huang J, Mei R, et al. Algorithms for largescale genotyping microarrays. Bioinformatics. 2003;19:1397-2403.

13. Zimin AV, Delcher AL, Florea L, Kelley DR, Schatz MC, Puiu D, et al. A whole-genome assembly of the domestic cow, Bos taurus. Genome Biol. 2009;10:R42.

14. Henrickson RL, Mjoseth JH. Tenderness variation in two bovine muscles. J Anim Sci. 1964;23:325-8.

15. Browning SR, Browning BL. Rapid and accurate haplotype phasing and missing data inference for whole genome association studies using localized haplotype clustering. Am J Hum Genet. 2007:81:1084-97.

16. Fernando RL, Garrick DJ. GenSel-User manual for a portfolio of genomic selection related analyses. In: Animal Breeding and Genetics. 3rd ed. Ames: lowa State University; 2009. Accessed January 23, 2013. http://www.biomedcentral.com/ content/supplementary/1471-2105-12-186-s1.pdf.

17. Kizilkaya K, Fernando RL, Garrick DJ. Genomic prediction of simulated multibreed and purebred performance using observed fifty thousand single nucleotide polymorphism genotypes. J Anim Sci. 2010;88:544-51.

18. Meuwissen THE, Hayes BJ, Goddard ME. Prediction of total genetic value using genome-wide dense marker maps. Genetics. 2001;157:1819-29.

19. Fernando RL, Garrick D. Bayesian methods applied to GWAS. Methods Mol Biol. 2013;1019:237-74.

20. Huang DW, Sherman BT, Lempicki RA. Systematic and integrative analysis of large gene lists using DAVID bioinformatics resources. Nat Protoc. 2009;:44-57.
21. Trevisan LC, Nogueira ARA, Nóbrega JA. Single vessel procedure for acid vapor partial digestion of bovine liver in a focused microwave: multielement determination by ICP-OES. Talanta. 2003;61:81-6.

22. Li JY, Paragas N, Ned RM, Qiu A, Viltard M, Leete T, et al. Scara5 is a ferritin receptor mediating non-transferrin iron delivery. Dev Cell. 2009;16:35-46.

23. Casas E, Duan Q, Schneider MJ, Shackelford SD, Wheeler TL, Cundiff LV, et al. Polymorphisms in calpastatin and mu-calpain genes are associated with beef iron content. Anim Genet. 2014;45:283-4.

24. Keresztes $G$, Mutai $H$, Heller S. TMC and EVER genes belong to a larger novel family, the TMC gene family encoding transmembrane proteins. BMC Genomics. 2003;4:24

25. Eide DJ. The molecular biology of metal ion transport in Saccharomyces cerevisiae. Annu Rev Nutr. 1998:18:441-69.

26. Morth JP, Pedersen BP, Buch-Pedersen MJ, Andersen JP, Vilsen B, Palmgren $M G$, et al. A structural overview of the plasma membrane $\mathrm{Na}+, \mathrm{K}+$-ATPase and H + -ATPase ion pumps. Nat Rev Mol Cell Biol. 2011;12:60-70.

27. Wood RJ, Ronnenber AG. Iron. In: Shils ME, Shike M, Ross AC, Caballero B, Cousins RJ, editors. Modern Nutrition in Health and Disease. Philadelphia: Lippincott Williams \& Wilkins; 2006. p. 248-70.

28. Bolormaa S, Pryce JE, Kemper KE, Hayes BJ, Zhang Y, Barendse W, et al. Detection of quantitative trait loci in Bos indicus and Bos taurus cattle using genome-wide association studies. Genet Sel Evol. 2013;45:43.

29. Huang W, Richards S, Carbone MA, Zhu D, Anholt RR, Ayroles JF, et al. Epistasis dominates the genetic architecture of Drosophila quantitative traits. Proc Natl Acad Sci U S A. 2012;109:15553-9.

30. Vasiliou V, Vasiliou K, Nebert DW. Human ATP-binding cassette (ABC) transporter family. Hum Genomics. 2009;3:281-90.

31. Pryce JE, Bolormaa S, Chamberlain AJ, Bowman PJ, Savin K, Goddard ME, et al. A validated genome-wide association study in 2 dairy cattle breeds for milk production and fertility traits using variable length haplotypes. J Dairy Sci. 2010;93:3331-45.

\section{Submit your next manuscript to BioMed Central and take full advantage of:}

- Convenient online submission

- Thorough peer review

- No space constraints or color figure charges

- Immediate publication on acceptance

- Inclusion in PubMed, CAS, Scopus and Google Scholar

- Research which is freely available for redistribution

Submit your manuscript at www.biomedcentral.com/submit
C) Biomed Central 